\title{
The effect of benzoic acid or its ethyl ester on rumen fermentation parameters
}

\author{
J Nousiainen \\ Valio Ltd, Farm Services, PO Box 390,00101 Helsinki, Finland
}

Benzoic acid (BA) or its fatty acid esters may be used as mould and yeast inhibitors in silage additives to improve the aerobic stability of silage (Lampila, 1983, patent FI 63328). Although $B A$ is not dissociated in the rumen $\mathrm{pH}$, it and especially its esters may have specific influence on the rumen ecosystem. The purpose of this work was to study the dose response of $B A$ or its ethyl ester (EB) on the rumen fermentation parameters in the continuous culture apparatus.

Two trials were done, first with $\mathrm{BA}$ and the second with EB. Three levels of each additive were added in the fermentors ; 0,25 and 50 (BA) or $0,15,30$ (EB) $\mathrm{mg} /$ day. The second level was calculated to represent the maximum amount in vivo. The fermentation apparatus and the design of trials as well as the treatment of rumen inocula was the same as described by Miettinen and Setälä (1989, J Agric Sci Finl, 61, 463-473). Six fermentors were used in a one-week-trial, two fermentors per treatment and the design was repeated on two consecutive weeks. The basic diet consisted of grass silage (500 $\mathrm{g} / \mathrm{kg}$ DM) supplemented with barley an oats (both 250 $\mathrm{g} / \mathrm{kg} \mathrm{DM})$. The feeds were dried and milled to pass $1 \mathrm{~mm}$ screen. The diet was fed at the rate of $26 \mathrm{~g} \mathrm{DM} /$ day/fermentor in two equal portions. Artificial saliva was infused into the fermentors to achieve the flow rate of $0.06 / \mathrm{h}$. $\mathrm{pH}$ was kept at 6.00 with saturated $\mathrm{Na}_{2} \mathrm{CO}_{3}$. Dry matter (DMD) and organic matter (OMD) digestibility, VFA production and microbial protein synthesis (MPS) were measured as described previously (Miettinen and Setälä, 1989).

The additives did not affect DMD or OMD of the basic diet significantly. The production of VFA and microbial protein remained unchanged as compared to control. In addition to total VFA production, also molar proportions of VFA were the same between treatments.

In conclusion, benzoic acid or its ethyl ester does not seem to affect rumen fermentation harmfully. They may be safely used in silage additives to improve aerobic stability.

\begin{tabular}{lcccccc}
\hline Item & \multicolumn{2}{c}{ Level $(\mathrm{mg} / \mathrm{d})$} & & \multicolumn{2}{c}{ SEM } & \multicolumn{2}{c}{ Significance } \\
Benzoic acid & 0 & 25 & 50 & $2 \mathrm{df}$ & Linear & Quadr \\
DMD (\%) & 50.1 & 43.1 & 45.6 & 0.8 & 0.139 & 0.101 \\
OMD (\%) & 34.4 & 37.1 & 34.8 & 0.8 & 0.853 & 0.273 \\
VFA (mmol/d) & 93.9 & 100.7 & 95.0 & 2.3 & 0.863 & 0.319 \\
MPS (g/d) & 65.3 & 69.5 & 68.1 & 0.5 & 0.170 & 0.135 \\
Ethyl benzoate & 0 & 15 & 30 & & & \\
DMD (\%) & 46.1 & 44.4 & 47.2 & 1.0 & 0.719 & 0.388 \\
OMD (\%) & 37.6 & 37.6 & 38.2 & 0.6 & 0.741 & 0.817 \\
VFA (mmol/d) & 101.9 & 101.9 & 103.1 & 1.4 & 0.761 & 0.860 \\
MPS (g/d) & 62.9 & 65.8 & 62.6 & 1.4 & 0.945 & 0.416 \\
\hline
\end{tabular}

